\title{
Philosophy and Aesthetic: To Begin with the Case of Western Postmodern Art
}

\author{
Shi-Ying Zhang \\ Faculty of Philosophy, Peking University, Beijing, China \\ Email: zhangsy1921@163.com
}

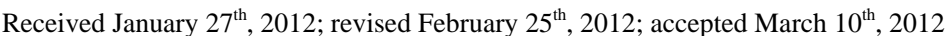

\begin{abstract}
Philosophy is, generally speaking, divorced from real life, and therefore, monotonous and rigid. But the author maintains that philosophy must be poetic. He advocates philosophy with beautiful features. Western postmodern art is closely related to real life, so art becomes life-oriented and vitalized. Philosophy may be inspired by Western postmodern art as follows: It should philosophize about life; philosophers may use reason to argue for an art-oriented realm of life and achieve a philosophy featuring beauty. Traditional Western philosophy is typical of pursuit of abstract concepts and ideals and an estrangement from the sensible world and life. To make philosophy achieve artistic beauty, we must bring to an end traditional Western philosophy. With the end of old philosophy, a new philosophy came into being with the name of "post-philosophy". One of the features of "post-philosophy" is the union of philosophy and poetry, which is no other than making philosophy achieve artistic beauty. The union of philosophy and poetry is also an important feature of most of traditional Chinese philosophy. Traditional Chinese philosophy, especially, that of Daoism is similar to Western post-modern art. Both of them stress the realm of life and uphold the beauty of life, mind and spirit. Since the middle of the last century, under the influence of traditional Western philosophy, Chinese philosophy lost its traditional beauty. To keep this beauty, we need to go further and understand philosophy as a discipline to upgrade the realm of life. The beauty of life realm comes before the beauty of philosophy. Therefore, Chinese philosophy needs to become life-oriented like postmodern art. Inheriting and developing Daoism philosophy while absorbing the philosophy of life shown through postmodern art, seems to be a good way for us to enhance the realm of life and pursue the beauty of philosophy.
\end{abstract}

Keywords: Postmodern Art; Perceptive Beauty; Spiritual Beauty; Post-Philosophy; The Union of Philosophy and Poetry; Traditional Chinese Philosophy

\section{Introduction}

Western postmodern art may be characterized as different from modern painting as follows: First, modern painting values visual beauty while postmodern art despises or opposes it for the sake of mental or spiritual beauty. Second, modern art advocates "art for art's sake" so much so that the art of painting was appreciated only by the few elites. By contrast, postmodern art is closely related to real life, so art becomes life-oriented. Third, modern art has some deep connections with reason and science, but postmodern art suggests that art should get free of all limits imposed by reason and science, and enjoy freedom in a realm of no differentiation.

We may see that the basic difference between modern painting and postmodern art is the change of aesthetic standard or point of view: modern painting considers visual "good-looking" to be beautiful (This doesn't mean, of course, that modern painting seeks visual beauty at the expense of artist realm.), and this is what aesthetics explains as "formal beauty" characterized by harmony, proportion and balance. In fact, this form of beauty is pleasing to our eyes and ears. The beauty of beautiful jades and beautiful eyes belongs to this category. By contrast, postmodern art regards as beautiful mental and spiritual freedom, especially a lofty and far-reaching realm of life. Visual or perceptual beauty certainly contains some elements of freedom, but they are not definite or clear enough. Let's take Marcel
Duchamp (1887-1968), father of postmodern art, as our example. Usually a door is either open or closed, but it can't be the unity of being open and closed. Duchamp designed, however, a door that is both open and closed. He made two doorframes for two walls at a right-angle connection. The two doorframes use the same door. When closed to this doorframe, it must be open to the other doorframe. This work of art by Duchamp intends to overturn a time-honored pursuit of opposition, division and separation in western tradition. This door was later taken into a color picture of life size and put on an exhibition. Many visitors lingered for a while, lost in thought. Were they attracted by visual beauty of the door? No, they weren't. Duchamp's thinking mode is quite close to that in Chinese tradition. Traditional Chinese thought, especially teachings of Yi Jing and Laozi, stresses unity of opposites, of Yin and Yang, of one in the other, of one in two and two in one. This is very different from the western thinking mode which stresses definition, division and differentiation, hence no relation between one and two. Western modernity stresses one-sidedly inflexibility of reason and science, and resulted in a stereotyped and uninteresting style of life and mentality. Duchamp's Door added to it an "interesting and humorous color" (Duchamp's words). Beauty of the Door cannot be appreciated by merely the "sense of eyes"; it calls also for the "sense of mind". Door provides us with artistic enjoyment, not in the form of visual or perceptual beauty, but in 
the form of mental beauty.

Due to his "sub-consciousness to combat perceptual beauty", (Pierre Cabanne and Trans., 2003) Duchamp went so far as to use mechanical drawings. His painting "Change from Virgin to Bride" does not have any physical image which may suggest visual sexuality, on the contrary, it is composed of mechanical lines, so humans were turned into "machines". Seen from left to right, however, this mechanical painting portrays the "change" a woman underwent step by step from a virgin to a young lady so much so that an instant image of a male peeper appears at the extreme right. At this instant "virgin" was turned into "bride". The title of the painting appears on the left-bottom corner which has the word "passage". This is the very "instant of change" from a virgin to a bride, a focus Duchamp was trying to think about and put forward in the painting. No sexuality or pornography, a most mysterious scene in human life, an embarrassing topic to many people, was depicted to the full. What viewers see here is not ordinary visual beauty, pleasing to eyes or ears only, which is what Duchamp combated, but a thoughtprovoking passage of life, which is also an aesthetic consciousness, a beauty of the realm of life, and a mental beauty.

Duchamp's objection to perceptual beauty went so far that he gave up painting completely and devoted himself to playing chess for a long time in order to arrive at a realm of life where differentiations disappear, things in the world are related to each other and freedom prevails. He said: "My life is my best work," "art serves thought," but not sight or perception. It is clear that Duchamp's art is not traditional or perceptive, for it tries to uncover directly the philosophy of life.

Duchamp's concept of art is life-oriented and his aesthetics philosophical and thought-provoking. This attitude is expressed more clearly in subsequent postmodern art. Mierle Laderman Ukles, a woman artist in New York, spent about a year living among cleaners and experiencing their life. On one occasion she stood at the entrance of a cleaning company, shook hands with and expressed thanks to over eight thousand cleaners, saying "Thank you for making New York full of vitality". The woman artist regarded this action as a special "work of art" for cleaners. The cleaners said: "We have never had such experience in our life. If this is art, we like it” (Wang, 2004). The artist filled up the gap between art and real life. Her action got completely free from visual beauty and embodied a beauty of the lofty realm of life. This is a beauty of loftiness in thought. Joseph Beuys (1921-1986), a famous postmodern artist in Germany, substantiated his "art of actions" in practical life. To take part in the campaign for parliament membership, to lead people to do cleaning in the woods, to see to planting over seven thousand oaks and the like were all considered to be his works of art. He hoped these works of art-artistic actions-might help to save human society and heal their heart. Art was turned into an art for upgrading the realm of life. To make the world perfect and agree to his ideals, he often did something unpractical, shouting like a child: "My intention is good". In the bottom of his heart was hidden an infant's heart that goes against the tide of public opinion.

Postmodern art moved from visually and perceptively aesthetic consciousness to philosophical thoughts of life and society. Some of the postmodern artists say it is a transition from "art" to "non-art". Words like this naturally remind us of Hegel's view that art will be replaced by philosophy. In fact, postmodernism and Hegel are definitely different. Hegel classified levels of arts by the degree to which mind may reach in overcoming matter: the more limited a form of art is by matter, the less free its mental activities will be, and a lower level it belongs to; on the contrary, the more unlimited a form of art is by matter, the more free its mental activities will be, and a higher level it belongs to. Symbolic art belongs to the lowest level of arts because here matter prevails over mind; by contrast, romantic art is the highest level of arts because mind prevails over matter. The top level of romantic art means that mind prevails over matter pure and simple, without any appeal to perceptive images, therefore it is able to know the highest reality with concepts (through the stage of religion)-the "Absolute Idea", which declares the end of art and the beginning of philosophy. We may see that in Hegel's thought the transition from art to philosophy means, in the final analysis, a separation of mind from matter, and thought from perception. Of course Hegel didn't say, as some researchers argue, that art should "die". He only said that "the form of art is no longer the highest demand of mind” ( $\cdots$ ihre Form hat aufgehört, das hörchst Bedürfnis des Geistes zu sein) (G. W. F. Hegel: Werke, 1981). Hegel did believe, however, that "the highest demand of mind" is its separation from matter and sensitivity to arrive at a super-sensible, "pure conceptual” philosophy. Comparatively speaking, the non-art as postmodern artists called it and as the "art of actions" mentioned above, is not at all super-sensible but real life. Hegel says that the highest certainty of mind is freedom. We believe he is right. But he believes in supremacy of reason, and argues that although art has gone through various stages of limitation such as the satisfaction of human demand for natural desires, knowledge and volitions, it is still bound by sensitivity and has not yet achieved absolute and complete freedom; it is in the stage of concept that mind is able to compromise at last the mutually-limited opposition, arrives at the fullest freedom and satisfies its highest need. "To grasp the concept of truth is the business of philosophy" (Diesen Begriff der Wahrheit zu fassen, ist die Aufgabe der Philosophie). (Hegel, 1981). Concepts may overcome, step by step, our natural needs and our needs for knowledge and volitions, finally they may go beyond all limits of human sensitivity. Hegel named such concepts "pure concepts". Aiming at a grasp of the "pure concepts", Hegel's philosophy has actually separated itself from real life, therefore from his point of view, life was boring, lack of colour and vitality, just opposite to the postmodern view that art should be life-oriented.

Modern western thought stresses the importance of reason, which was originally a product of the counter-movement to theocracy in medieval times and has played a positive role in liberating humanity and mobilizing their free creativity. Unfortunately, supremacy of reason understands humanity onesidedly as mere subject of reason, ignoring or denying such non-reason aspects as human feelings, sensations or instincts. Hegel didn't reject human feelings, in fact he highly praised Aristotle for his criticism of Socrates-Plato's definition of morality lacks illogical and irrational elements. He said clearly, however, that "morality should restrict passions", and "something rational should prevail in morality”. (Hegel: Werke, 1981). His "pure concept" theory calls off all irrational elements in particular. As a matter of fact, humanity and their history and culture must be a unity of reason and non-reason. Rule of mere reason may turn life into a tough and rigid formula. Hegel claims that mind may enjoy freedom in "concepts", but it is these rationalistic "concepts" that make humanity lose his integrity, creativity and freedom. Postmodernism claims that irrational 
elements such as sensations, desires, instincts and the like are the source of our life and creativity. Postmodern art, especially some of the "art of actions", is no other than free and full expression of our natural features, primitive desires and passions. The French postmodern artist Yves Klein (1928-1962) went so far as to create a work of art named Emptiness. There is a mere empty house and nothing else for visitors to see. Many visitors laughed and left, but the great writer Albert Camus (1913-1960) saw something deep and made a very philosophical remark in the notebook: "The emptiness is filled with power". On the strength of his skills in judo, this artist even jumped off from the second floor of a building to show that he was flying in emptiness. Works of actions such as this may seem ridiculous, yet they do show human impulse to be free and creative. Probably the impulse is radical. Free creation is the feature of artistic aesthetics. In postmodern art it extends from visual field in the past to the field of real life, so it becomes more definite, vivid and deep. Hegel argues that art should give way to philosophy, a view that fails to extend the freedom of art; to make matters worse, it throttles this feature altogether. By contrast, postmodern art argues for "non-art”, a view that makes life art-oriented and realm of thought upgraded. Art's giving way to philosophy, as Hegel understood it, resulted in a life lack of colour, vitality and formularization of philosophical concepts.

Postmodern art does have many radical and ridiculous elements. For example, some artists of actions shut themselves up in a cage to gain experience and haven't communicated with the world for a year; some kept running between two walls dozens of meters apart till they were exhausted and fell, and they called it the "art of body". Things like this are many, and they tried to break new ground in order to show their unique realm of artistic life. As a matter of fact, few can see what mental realms these extraordinary works of life are trying to express. Paying no respect to conventions and following the course of nature, postmodern art presents itself as an anti-traditional thought. Supremacy of reason and science has dominated western mind for a long time, a view that advocates blindly division and analysis, and insists on universality of concepts, unchangeableness of standards and eternity of laws, hence a rigid and uninteresting life and a dull and boring philosophy. Consciously or not, postmodernism made use of traditional Chinese mode of thought, which is characterized by fuzzy boundaries and universal connectedness, to combat western tradition, but sometimes it goes so far as appealing to some unacceptable or unreasonable actions. The tenet of postmodern arts is freedom of thought and unrestraint of life, a view that calls for our special attention and appreciation.

As mentioned above, Duchamp considered his life his 'best work of art.' He said clearly that his philosophy of life is complementarity of opposites and no-differentiation. Duchamp had a great personality, detached, indifferent to fame and fortune, ready to help, so he was very popular with the people around him. Chinese views like "making all things equal" and "carefree roaming" by Zhuangzi, or Zen Buddhist view that even carrying water and cutting firewood are oriented by Zen, may be summed up as follows: all things are connected, and A can be $\mathrm{B}$ and vice versa without restraint; thoughts like this seem to be a mirror of Duchamp's realm of life and philosophy. As a matter of fact, "non-art" or "non-beauty" by Duchamp belongs to the highest level of art and beauty. Some postmodern arts in the sixties of the last century were radical and went astray when they were learning from Duchamp and Chinese Zen Buddhism; leaving this aside, Duchamp's art of life should be counted the best representative of western postmodern art. However, postmodern art typical of Duchamp is not philosophy after all; most postmodern arts are philosophical, yet to be philosophical is short of philosophical theory. As a discipline, philosophy must use concepts and argument, by contrast, postmodern art is strong in real life but weak in argument. Step by step Hegel moved away from real life and entered into a world of pure concepts and pure reason, thus depriving philosophy of any vitality of life and beauty of art. By comparison, postmodern art is an art of life, not a discipline that makes use of concepts and arguments at all. Of course we should not ask artists to become philosophers, yet we have our reasons to ask philosophy to share in artistic beauty. Philosophy may be inspired by postmodern art as follows: It should philosophize about life; philosophers may use reason to argue for an artoriented realm of life and achieve a philosophy of beauty.

\section{Part II}

Beginning with Plato, traditional western philosophy has almost become synonymous to "metaphysics", a tradition that is typical of subject-object dichotomy, supremacy of reason, pursuit of abstract concepts and ideals, and an estrangement from the sensible world and life. Plato plays down the importance of art, so he argues that poets must be driven out of his Republic. He teaches that our supreme happiness and pleasure lie in a rational pursuit of abstract concepts, thus human feelings and passions are confined to a minimum. Traditional western philosophy culminated in Hegel, his theory that art should give way to pure-concept philosophy remains an extension and variation of Platonism (Zhang, 2007). To make philosophy achieve artistic beauty, we must bring to an end traditional western metaphysics. With the end of old philosophy, a new philosophy came into being with the name of "postphilosophy” or "post-modern philosophy". One of the features of post-philosophy is the union of philosophy and poetry, a view that presents itself clearly in Heidegger's later philosophy, while Derrida went further in removing the fence between the two (Zhang, 2007). The so-called union of philosophy and poetry is no other than making philosophy achieve artistic beauty.

To become beautiful, philosophy must unite life closely. As mentioned above, a philosophy of concepts, divorced from life and super-sensible, cannot produce the beauty of philosophy. Philosophy is concerned with "rational, systematic and methodological thoughts about the important questions of life” (The New Encyclopedia Britannica,1993). Life has various aspects and forms: science, morality, aesthetics and so on belong there. Deep inquiries about different aspects of life ("rational, systematic and methodological reflections", or as the Chinese proverb says: Keep asking questions till we arrive at the bottom of the matter,打破沙锅问到底), have culminated in different philosophies like the philosophy of science, of economics, of politics, of morality, of aesthetics and the like. In Chinese, we usually leave out the preposition "of", hence "scientific philosophy", "political philosophy" and so on. To reflect on natural events, we discovered laws of nature; and the same is true to the laws of politics and morality. Certain disciplines must be concerned with the laws of certain events. Physics is concerned with physical laws, and politics political laws, etc. 
Therefore some argue that philosophy is different from other specific disciplines in that it is concerned with the most universal laws. Certainly, laws are always universal and unified. The "most" universal law must have the "highest" universality and unification. Thus the view goes further and argues that philosophy is the only science.

Our reflections on human life certainly include a pursuit of universal laws, even the "most" universal law. Sciences are systems of knowledge; the science of the "most" universal law is also a system of knowledge. But is it true that our reflections on life stop as soon as they arrive at a system of knowledge? I think a mere grasp of certain law, including the "most universal law", cannot count as the zenith of our reflections on life or philosophy. Probably it is true that philosophical pursuits begin as soon as scientific laws present themselves to us. Philosophical reflections are characterized by keeping asking questions till we reach the bottom of the matter: What is the ultimate ground of these laws? What attitude should we take toward these laws? And why these attitudes? Questions like this are proper to philosophy, so none of the other sciences can take its place. Questions like these may be simply called the question of life realm. This is the ultimate question that philosophy should investigate. Philosophy is the science of life realm directed at enhancing human realm of life (not as some claim that "the business of philosophy is to grasp the most universal law”). The realm of life an individual or a group have determines their philosophy, hence pessimism, optimism, egoism, anthropocentrism, non-anthropocentrism, etc. People in different walks of life have different realms of life, thus different philosophies. Different nations have different realms of life, thus philosophies of different nations. People of different religious beliefs have different realms of life, thus different philosophies of religion. People of different times have different realms of life, thus philosophies of different times. Questions that philosophy pursues and reflects on are not those that science can answer, on the contrary, they do not have a final or decisive answer. Therefore the only scientific philosophy does not exist. Of course, due to some common environment of life, people of the same nation with the same religious belief in the same period of time may have the "resonant" ("sympathetic") philosophy; however, the "resonant" does not mean it is the only true philosophy (Zhang, 2008).

According to the degree of mental freedom, I divide life realm into four different levels: the lowest level is the "realm of desires". People of this realm know nothing but satisfying their most basic needs of life. "Mengzi" said: "Eating and having sex are human nature". This is the realm of desires. As Mengzi claimed, it is "not far from the life of animals", not free at all. The second level is the "truth-seeking realm". Man of this realm has gone beyond the level of simply satisfying his most basic needs for existence and become eager to know the world so that he may understand the orders and laws of the tings there. Ignorance means limitation. With knowledge and various laws, man's mental freedom will make very great progress. So "truth-seeking realm" gains certain degree of freedom. We usually say that "to know necessity is to gain freedom"; as a matter of fact, this is only half of the story. As discussed above, having grasped laws and necessities, a new question turns up: How are we to look at them? Following them passively with moans cannot be counted as freedom; by contrast, following them actively, as Nietzsche suggested that we "embrace necessity with love”, will lead us to true freedom. In the pursuit of science, man is a knowing subject who is concerned to understand external objects. To define philosophy as a science of universal laws will lead to a monotonous understanding of human life, but this is by no means a philosophy of freedom, not to mention the beauty of it. With the development of science and the socialization of individuals, man will come to see that he and other things in the world as well as other people can be integrated into a unity, and scientific pursuit cannot be separated from morality (Zhang, 2007). With this knowledge, life moves into its third realm - the realm of morality, where man is freed, in certain extent, from the externality between subject and object and has gained more freedom. (Between scientific activities and moral activities, there are economic and political activities, which include both our natural desires (for example, economic activities cannot separate themselves from natural desire for self-preservation) and non-natural aspects. The former is close to scientific activities, the latter moral activities. Therefore, the freedom of economic and political activities is also between science and morality. The four realms of life I am discussing here are recapitulative, thus I did not classify a separate realm of life for economic and political activities). But morality is always conditioned by the distance between ideals and reality, when subject and object have not reached a complete integration, of which the moral "ought" is an expression. Realization and completion of morality means both its zenith and its end. Here begins the fourth realm of life, namely the "aesthetic realm". This realm includes morality but goes beyond it, too. In this realm man acts by neither the restraint of moral duties (even if it is based on our wills), nor the moral "ought", but by a natural state of mind where man and all other things of the world are integrated into a whole. "Being natural" is used in Laozi's sense which claims that "Dao imitates nature", different from any "ought-ism". The latter is not completely free, but the former is. Man of the aesthetic realm acts necessarily by morality, yet he remains "natural"-free to do what he should without any restraint.

As mentioned above, Hegel believes that freedom is the nature of mind. By different levels of freedom, he classifies human activity into many levels from the lowest satisfaction of basic desires to the highest pursuit of mind. Unfortunately he is just one step short of success, for he argues that only through a complete separation from all human activities, including that of arts and arriving at the stage of pure concepts, can we achieve the highest freedom (Hegel, 1981). By comparison, the four realms of life I am discussing here are connected to concrete life all the time, where life and freedom go hand in hand. Generally speaking, life must be some interwovenness among these four realms, where some people are dominated by lower realms while others by some higher ones. Broadly, lower realms are included in higher realms, but they cannot separate from each other; that is to say, a man of aesthetic realm, such as a real poet, cannot but satisfy his basic needs for existence. As a man of aesthetic realm and a poet, however, he may look at this part of life for basic existence in an aesthetic perspective. The business of philosophy is to enhance realm of life. In other words, it is engaged in upgrading a common realm of life to aesthetic realm; in Schiller's words, its purpose is to create a personality where perceptions and reason are united and "aesthetic intuition" is achieved-a person of "freedom" and "integrity".

I have stressed in many of my writings that aesthetics may be different in value. Beauty of forms, perceptions and visions belongs to the lower level, while beauty of mind and life realms 
a higher level. As mentioned above, the transition of modern western art to its postmodern form includes a change from an emphasis on the beauty of form, perception and vision to that of mind and life realm. We should say that this is a progress in aesthetics. I think the zenith of 'aesthetic realm' is characterized by a high and far realm of life, typical of a unity of all things in the world, of heaven and man, and no limitations among things. The life of Duchamp, father of postmodern art, may be considered to belong there. Regretfully, as an artist, Duchamp did not give detailed descriptions of his realm of life, and the descriptions lack for rational reflections and systematic argument, so he cannot be counted a philosopher. Postmodern artists after Duchamp enjoy an aesthetic realm of life, but they gave less rational reflections and theoretical arguments, so actions are much more than words with them, and the beauty of philosophy is out of the question.

By the principle that art must be combined with life, we can see clearly that an aesthetic realm usually shows itself in some lower levels of life and results in various beauties of life at different levels: Seen in a perspective of subject-object dichotomy, if one regards sexual love, the lowest "desire”, simply as a tool to satisfy his animal instincts, as people in lower realms of life usually do, then beauty is out of the question; on the contrary, seen in a perspective of man-world unity, one will experience a beauty in sexual love. "A soft jade and warm fragrant flowers in full bosom ... Spring comes and flowers show their beautiful colours $\cdots$ Dew drops fall on the peony in blossom”. Thus sexual love becomes poetic and beautiful, a beauty that is not only visual and perceptive, but also contains something of a higher level-a beauty of mind or spirit. I call this beauty of life that shows itself in sexual love "emotive beauty". Scientific activity of a higher level can be put in the same perspective. Seen in a perspective of subject-object dichotomy, science is nothing but universal laws of external objects that man as subjects is trying to uncover; with these laws it makes objects serve man's purpose, just like the view which regards philosophy as the only science that is engaged in discovering the most universal laws. If this is the case, then beauty is also out of the question in science. Seen in a perspective of man-world unity, however, we can experience beauty in scientific activity: First of all, we may experience a formal beauty derived from harmony and integration of the universal law and theorem (not to mention the beauty that appears under a microscope or an astronomical telescope). But mental or spiritual beauty is more important. For example, Einstein once said that he embraced a "religious feeling" for the cosmic order and intelligibility ("Intelligibility" refers to the unity between man and things); he believed that this feeling, derived from an impersonal God, is the driving force of scientists to pursue continuously physical studies. He called this impersonal God the "God of Spinoza”. In my view, the "religious feeling" of Einstein belongs to a higher level of aesthetic realm, as a beauty of sublimity. Furthermore, I believe that scientific activities characteristic of disinterested free spirits may bring scientists a sense of pleasure, and this also belongs to a higher level of aesthetic realm. To all this beauty shown in scientific activities I gave the name of "scientific beauty". (See my discussions in Chapter Five: Science and Aesthetics, Realm and Culture. Renmin Press, 2008). Moral activities are derived from some "ought", close to its aesthetic counterpart; if one does the "ought" freely and naturally, then he or she achieves a "moral beauty", an uncommon phrase in our language. In one word, life-the relation between man and the world, means not only the use of certain tools, but also a deep level of aesthetic enjoyment. But it is not the case that everyone may reach the realm of aesthetic enjoyment: Everyone has sexual desires, but only those who have reached aesthetic realm may experience "emotive beauty"; the same is true to the world of science, namely, only those scientists who have reached aesthetic realm may experience "scientific beauty" (Of course, beauty of a low level such as visual or natural beauty shown under a microscope or astronomical telescope, may be within the reach of all scientists, but I do not suggest that we take them as the main instance of "scientific beauty"). Western postmodern art gives expression to various beauties of life, but it lacks theoretical discussions and analyses, without making difference among different levels like me. Philosophy characterized by beauty aims at reflecting on and rationalizing aesthetic life.

\section{Part III}

Western "post-philosophy" rejects the weakness of traditional philosophy which claims super-sensibility, opposition of dichotomy (including subject-object division) and the supremacy of reason and science, but stresses realm of life, so it enjoys a beauty of philosophy. Heidegger, Derrida and other philosophers argued like this. Before them, Nietzsche is a case in point. He pointed out that "Compared with artists, scientists degrade and limit life", "Art is more valuable than truth". Nietzsche argues that "ignorance is preferable", and the highest realm of life is that of "drunkenness" and free detachedness. Moreover, he contended for mental vision. All these discussions are not only vivid and detailed elaborations on the beauty of philosophy, but also good examples for us to understand this kind of beauty (Zhang, 2007).

Ancient Chinese believed in "heaven-man unity", a view that enables most of traditional Chinese philosophy to combine with poetry. Therefore, works of ancient Chinese philosophy are usually that of literature, and philosophers were usually literary writers. This is because "heaven-man unity" is a realm of aesthetics without me-things or subject-object division, on which most of the traditional Chinese philosophy are reflections and elaborations. Confucianism makes moral realm the highest realm of life. It also advocates "heaven-man unity", but its "heaven" is moral to a great extent. Despite all that, its "heaven-man unity" remains to be poetic, for it tries, through a poetic and aesthetic consciousness, to turn a moralized "heavenly principle” into a spontaneous pursuit of the mind. By contrast, Daoism clearly regards aesthetic realm the highest realm of life, and its philosophy features the beauty of philosophy.

Chapter Twelve of Laozi writes: "Too much colour blinds the eye, Too much music deafens the ear... In this way the gentle care for people: They provide for the belly, not for the senses". It seems that Laozi is dening visual beauty, but in his ideal society he still teaches that people should "eat well and dress well” (Laozi, 80). We see that Laozi is not totally denying visual beauty. He intends to emphasize not visual beauty but mental or spiritual beauty. He described the realm as follows: "My heart is foolish, muddled and cloudy"; "But I am tranquil and wandering, like a newborn before it learns to smile"; "The people are busy with purpose, where I am impractical and rough" (Laozi, 20). Laozi called this realm "profound sameness” (玄同) and the people there are “fed at nature’s breast” 
(贵食母), namely they understand Dao, so they pay no attention to personal gains and look dim and dull. This is Laozi's ideal personality. Though as short as about five thousand Chinese characters, Laozi contains the earliest and also rich philosophical arguments and elaborations in Chinese history, whose very purpose is to discuss ontological basis of the aesthetic realm namely, the Dao. It is the first work that can be called "philosophy" in Chinese history, and also the first work of philosophy that embodies the beauty of philosophy.

Based on Laozi's philosophy of Dao, Zhuangzi developed Laozi's "profound sameness" into a mental realm of "heavenman unity" where "Heaven, Earth, and I were produced together, and all things and I are one”, a realm that is more poetic and beautiful than that of Laozi's "profound sameness". "Butterfly dream” is Zhuangzi's most vivid and beautiful description of his realm of "heaven-man unity".

Zhuangzi's discussions of aesthetic freedom are especially brilliant. This expresses itself in his theory of "waiting for and not waiting for" when he said that "There was Liezi, who rode on the wind and pursued his way, with an admirable indifference (to all external things) $\cdots$ but though he had not to walk, there was still something for which he had to wait. But suppose one who mounts on (the ether of) heaven and earth in its normal operation, and drives along the six elemental energies of the changing (seasons), thus enjoying himself in the illimitablewhat has he to wait for? Therefore it is said, The Perfect man has no (thought of) self; the Spirit-like man, none of merit; the Sagely-minded man, none of fame”. (Zhuangzi: Enjoyment in Untroubled Ease). Riding on the wind makes it unnecessary for one to walk, but he still "waits for something" - he depends on the wind, so this cannot count as untroubled ease or complete freedom. Common people occupy themselves in pursuing wealth and position, and regard them as freedom; in fact, this freedom is still "waiting for something", namely, it's waiting for wealth and position to satisfy itself. It will become completely limited as soon as wealth and position fall short of expectation. This is due to its "waiting for". Not waiting for anything at all is the only way to real freedom or untroubled ease, and this requires "not waiting for"-not dependent on anything external. If one can "go" the right way of heaven and earth, and "follow" the changes of yin and yang, in one word, if one can follow the course of nature and reach the realm of "heaven-man unity", he will become independent of all things in the world and achieve real freedom and untroubled ease. "The Perfect man, the Spirit-like man or the Sagely-minded man" may forget himself and get free from the entanglements of wealth and position, hence a person of real freedom and untroubled ease. In other words, "not waiting for" means to follow the course of nature in the realm of "heaven-man unity", not limited by things ("things outside of us") in the world of common people. This freedom is the feature of what Schiller called "games", namely "aesthetics". Zhuangzi inherited and developed Laozi’s view that everlasting Inner Power "comes back again to nativeness" (Laozi, 28); he rejected all ornamental beauty but advocated a mental beauty that turns up truthfully and naturally (Zhang, 2007). Moreover, Zhuangzi argues that, to create this beauty, one must have a "rambling" mind which is different from a common mind. A rambling mind refers to an emotion with which aesthetic subjects transcend finite reality and achieve infinite emptiness in the realm of heaven-man unity. Zhuangzi made a vivid analogy: If there is no emptiness in an apartment, grudges are likely to develop between a mother and her daughter-in-law; likewise, if mind does not ramble in the sky, the six orifices of the body are not likely to enjoy harmony. That is to say, emptiness ("rambling in the sky" or "a rambling mind") serves to "harmonize" (和) finite things in reality. To achieve harmony, real things must appeal to surreal "emptiness". "Rambling mind" actually means that mind rambles in emptiness; seen in this way, the word of "emptiness" is the kernel of beauty with Zhuangzi and all Daoist philosophy (Zhang, 2007). Zhuangzi's analyses of "rambling mind", "emptiness" and "the empty apartment that is filled with light through it” (Zhuangzi: Man in the World), remind us spontaneously of the above-mentioned French postmodern artist Klein and his work Emptiness. Zhuangzi is an ancient Chinese, Klein a contemporary westerner; one is a philosopher, the other an artist. Ancient and contemporary, Chinese and western, different minds seem to shine through each other and illuminate each other; art (beauty) and philosophy are different in method, but similar in thought.

In the philosophy of Zhuangzi, "emptiness" is beautiful. This means a transcendence over the three of the four realms I have discussed above, but not a simple negation. Zhuangzi is neither a nihilist, nor an ascetic. He teaches that "The Perfect man has no (thought of) self; the Spirit-like man, none of merit; the Sagely-minded man, none of fame”. This means neither that all is nothing, nor that things like personal desires, wealth and position, morality and principles are not important, but a transcendence over "desires", "principles” or "morality”. When his wife died, Zhuangzi drummed on a basin and sang. Huizi asked for the reason and was replied as follows: "When she first died, was it possible for me to be singular and not affected by the event? But I reflected on the commencement of her being. She had not yet been born to life $\cdots$ There is now a change again, and she is dead. The relation between these things is like the procession of the four seasons from spring to autumn, from winter to summer. There now she lies with her face up, sleeping in the Great Chamber; and if I were to fall sobbing and going on to wail for her, I should think that I did not understand what was appointed (for all). I therefore restrained myself! (Zhuangzi: Zhuangzi. Perfect Enjoyment). We see that the drumming on the basin and singing of Zhuangzi implies not at all that he was callous or heartless, but a far and high realm of mentality he achieved to follow actively the course of nature when he was struggling out of his painful loss.

\section{Part IV}

It seems neither fish nor fowl when we compare the philosophy of Zhuangzi with western postmodern art: one is philosophy and the other art, two different areas. How are we to make comparisons? But there are some similarities (communivation) between the two in their thoughts, so it must be interesting and important if we make the comparison. Without his philosophical explanation to Huizi, Zhuangzi's drumming on the basin and singing can be counted very well as an excellent work of art in the postmodern "art of actions". We feel postmodern art is "grotesque" and hard to understand, but Zhuangzi's drumming on the basin and singing is not. Why? Because Zhuangzi is a philosopher and has made philosophical explanations for his action. On the contrary, Emptiness as a work of the postmodern artist Klein, made visitors laugh and leave without any reflection, since he was not a philosopher and has not provided such philosophical expositions. Fortunately 
the great writer Camus has left incisive comments that "Emptiness is filled with power". Thanks to his words, people begin to understand this work of art. In reality, we may say that the hearts of Zhuangzi and Camus have a common beat when the former said that "the empty apartment is filled with light through it", and "Grudges are likely to develop between a mother and her daughter-in-law if there is no emptiness in an apartment”, and when the latter made the comments, an excellent interpretation of Klein's work. A philosophical discussion of the postmodern work of art Emptiness may well become the philosophy of Laozi and Zhuangzi. Why is Zhuangzi's philosophy or that of Chinese Daoism so similar to western postmodern art? The reason is that both of them stress the realm of life and uphold the beauty of life, mind and spirit, the core of which is to break down limits and enhance communication and free creation, therefore it is not visual or perceptive beauty. The beauty of art and philosophy is thus combined. The difference lies in the fact that they are products of different times and national traditions: postmodern art is post-scientific culture in the west, while the Daoist philosophy pre-scientific culture in China. Postmodern art is a reaction to and criticism of the supremacy of reason and science, a modern view in the west which simply stresses definition and analysis; on the other hand, due to inflexibility and solidification of the tradition, postmodern art failed to free itself from the thinking mode of strict division and separation, hence going from one extreme to the other. That is to say, modern art claims separation of art from life and dominion of art, on the contrary, postmodern art (art of actions or bodies) claims to reject art and beauty; modern art stresses visual and perceptive beauty, while postmodern art refuses both altogether, stressing thought and realm of life so much so that it called painters to give up painting. The watchword of postmodern artists is to "blur" the distinction between art and life, a view that intended to oppose the traditional thinking mode; as a matter of fact, however, it separates life from art and mental beauty from visual beauty, falling into the set pattern of traditional thought. This is the origin of some unconventional works of life and of actions purposely designed by postmodern artists. I think it is a big mistake with western postmodern art when it absolutely opposed visual and perceptive beauty to that of mind and life.

\section{Part V}

Laozi-Zhuangzi philosophy and that of Daoism in China belongs to a primitive thought typical of heaven-man unity. Compared with the traditional mode of thought in the west, obviously it lacks scientific definition and clear-cut analysis. Though Laozi-Zhuangzi philosophy and that of Daoism include some argumentation, so they can also be regarded as reflective philosophy, but they think in images, and poetry usually overtakes philosophical analysis - they are too simple after all. Nowadays when science is flourishing, Chinese philosophy cannot stay in its pre-scientific simplicity; its future development may be like this: We should keep the beauty of Laozi-Zhuangzi philosophy but absorb all the strong points in western science and culture, and upgrade our ability in making analysis so that traditional Chinese philosophy may take on a brand-new look in the world.

Since the middle of the last century, under the influence of modern western philosophy, Chinese philosophy has been dominated by a thinking pattern of subject-object dichotomy, believing that philosophy is concerned with finding the most universal laws of external things while man is regarded as subjects and things objects. Thus philosophy lost its traditional beauty and strength. To keep this beauty, we cannot stop either with the definition that the business of philosophy is to uncover the most general laws of the world, or with the thinking mode characteristic of subject-object dichotomy, on the contrary, we need to go further and understand philosophy as a discipline to upgrade the realm of life. The beauty of life realm comes before the beauty of philosophy. Therefore, Chinese philosophy needs to become life-oriented like postmodern art. Inheriting and developing Laozi-Zhuangzi philosophy while absorbing the philosophy of life shown through postmodern art, seems to be a good way for us to enhance the realm of life and pursue the beauty of philosophy.

\section{REFERENCES}

Cabanne, P. (Trans.) (2003). Dialogues with duchamp. Beijing: China Renmin University, 46.

Wang, R. Y. (2004). Through duchamp. Beijing: China Renmin University. 221-223.

Hegel, G. W. F. (1981). Theorie werkausgabe. Werke. Berlin: Suhrkamp Verlag. S134-S144, S223.

Zhang, S.-Y. (2007). Realm and culture. Beijing: Renmin Press. 125130, 160-162, 291.

Zhang, S.-Y. (2007). Relations between heaven and man (2nd ed.). Beijing: Renmin Press. 157, 315-329.

The New Encyclopedia Britannica (1993). 25. 733.

Zhang, S.-Y. (2008). Journey home: My life of philosophy. Beijing: Renmin Press. 114.

Zhuangzi. Zhuangzi. Perfect enjoyment. 